Supporting information

\title{
Aliphatic/Aromatic Polyimide lonomers as a Proton Conductive Membrane for Fuel Cell Applications
}

\author{
Naoki Asano, ${ }^{\ddagger}$ Makoto Aoki, ${ }^{\ddagger}{ }^{\ddagger}$ Shinsuke Suzuki, ${ }^{\ddagger}$ Kenji Miyatake, ${ }^{\dagger}$ \\ Hiroyuki Uchida, ${ }^{\ddagger}$ and Masahiro Watanabe ${ }^{\dagger},{ }^{\star}$
}

Clean Energy Research Center, and Interdisciplinary graduate School of Medicine and Engineering, University of Yamanashi, 4 Takeda, Kofu 400-8510, Japan, and Fuji Electric Advanced Technology Co., Ltd., 1 Fujimachi, Hino 191-8502, Japan

E-mail: m-watanabe@yamanashi.ac.jp

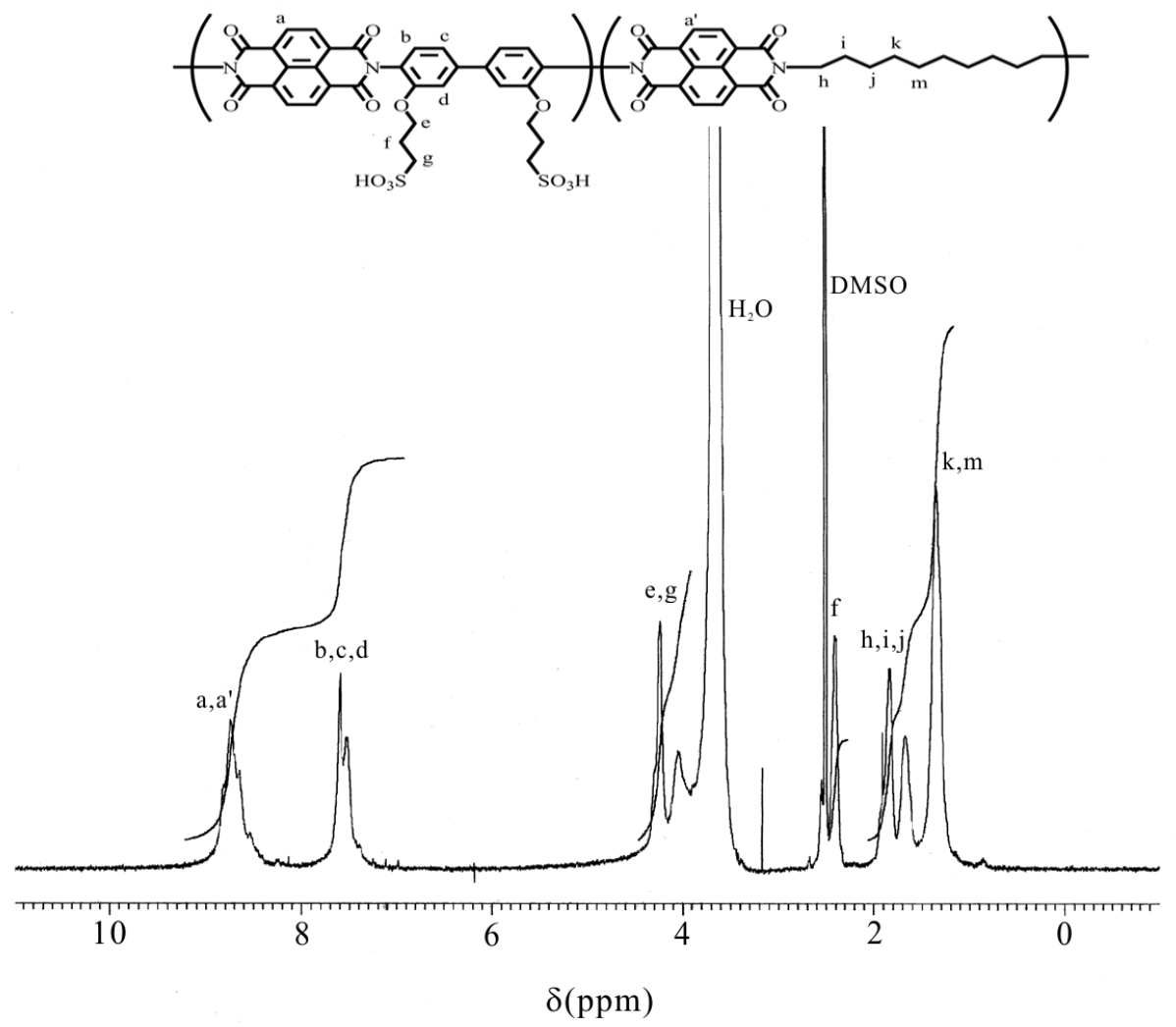

Figure S1. ${ }^{1} \mathrm{H}$ NMR spectrum of $\mathbf{1 c}(\mathbf{5 0})$. 


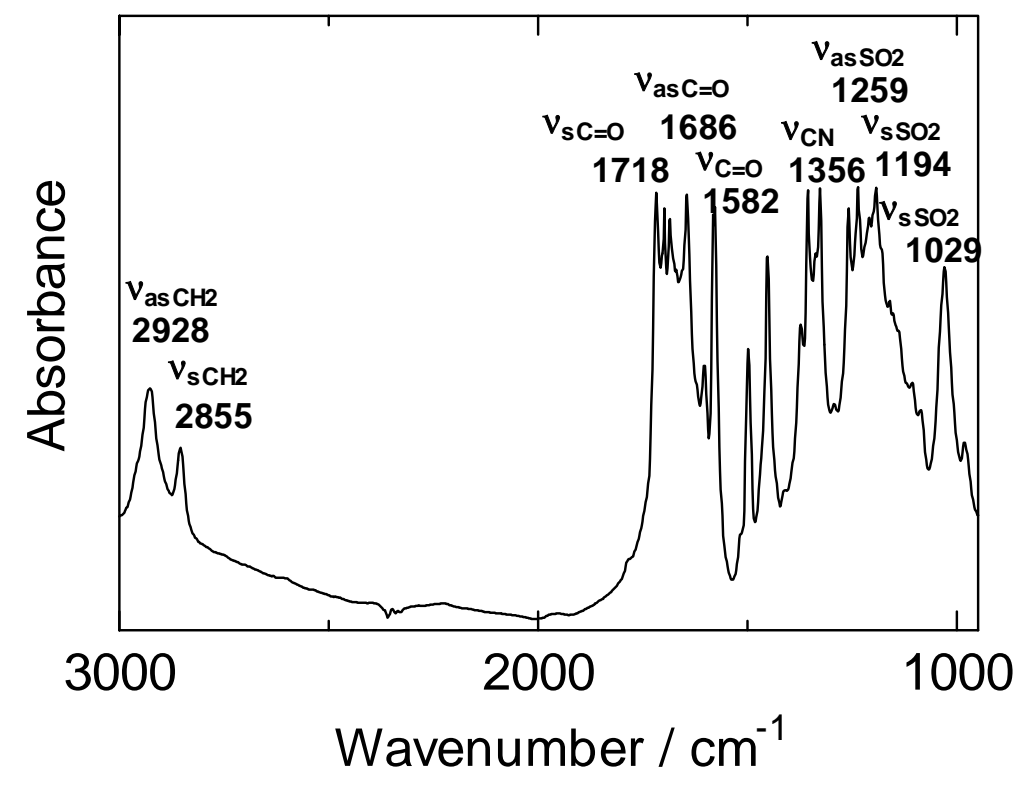

Figure S2. IR spectrum of $1 \mathrm{c}(\mathbf{5 0})$.

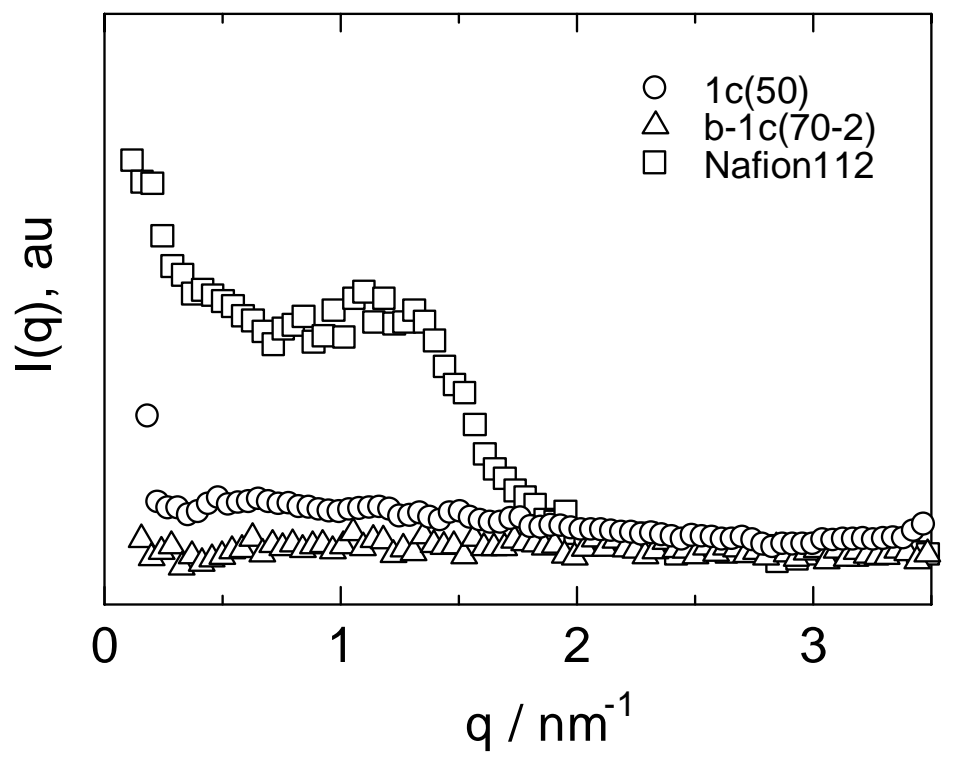

Figure S3. SAXS patterns of 1c(50), b-1c(70-2), and Nafion 112. 


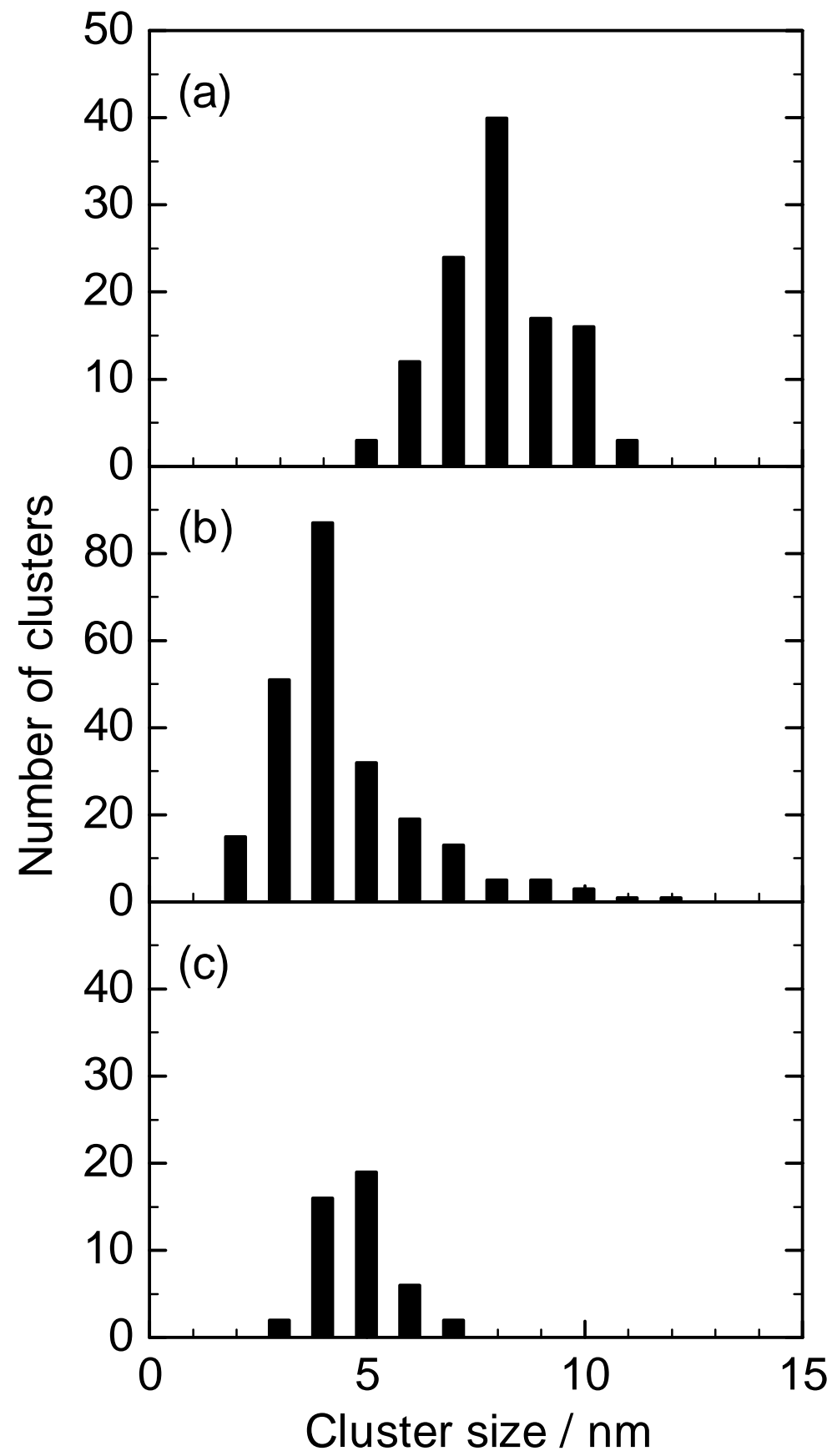

Figure S4. Cluster size distribution of $1 \mathrm{c}(\mathbf{5 0})$ (a), 1c(70) (b), and b-1c(70-2) (c) in Figure 5. 

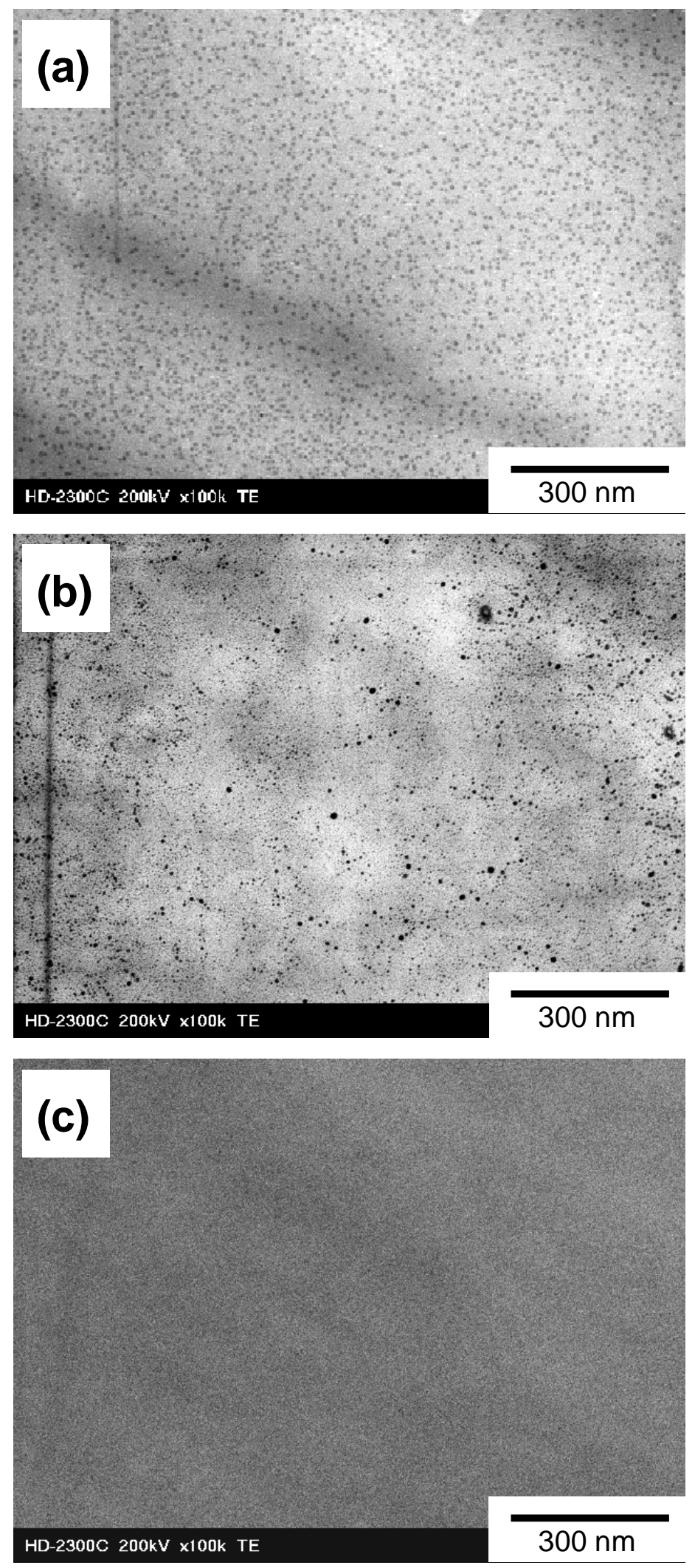

Figure S5. STEM images of $\mathbf{1 c}(\mathbf{5 0})(\mathrm{a}), \mathbf{1 c}(\mathbf{7 0})(\mathrm{b})$, and b-1c(70-2) (c). 


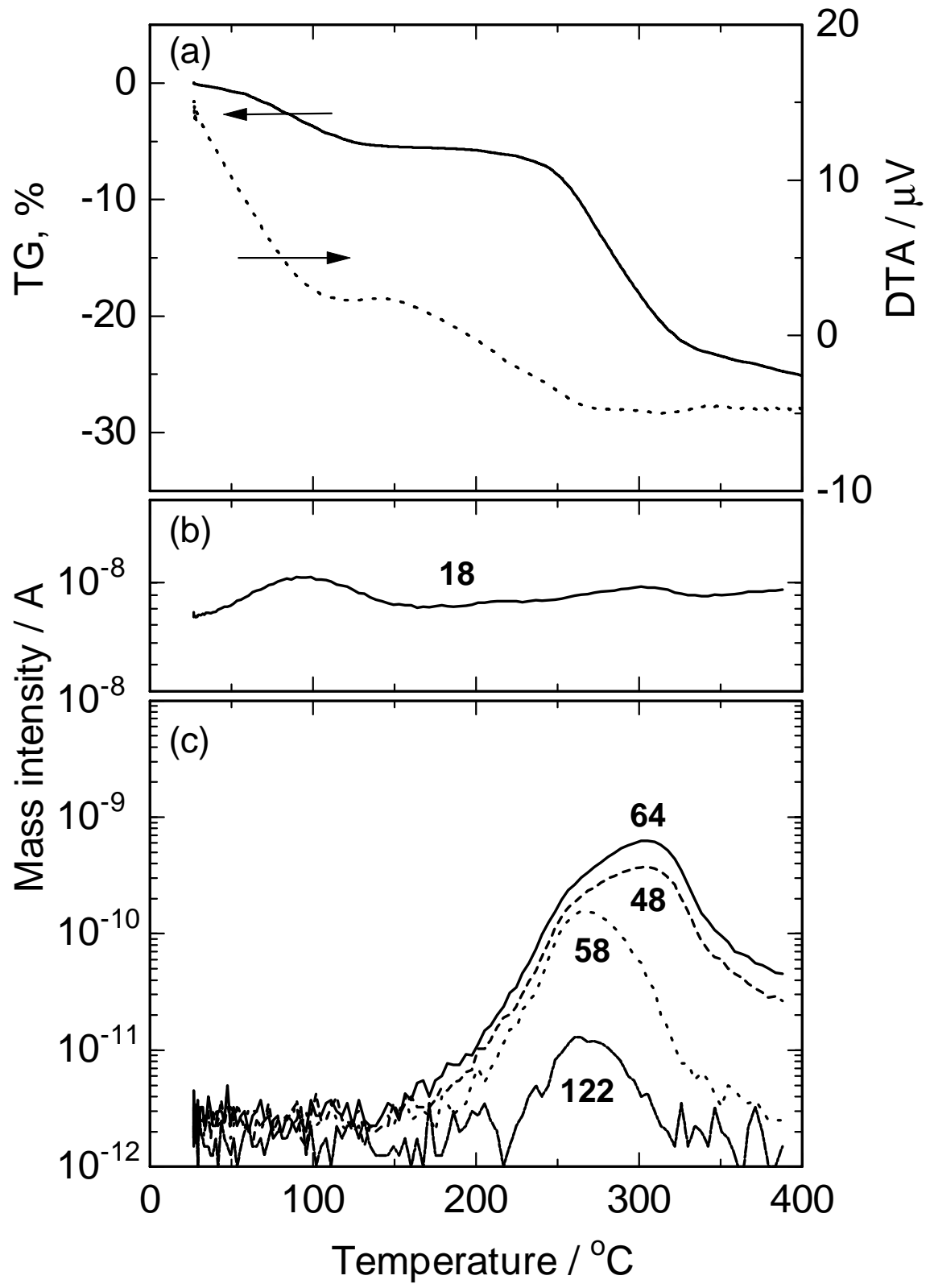

Figure S6. TG/DTA (a) and MS (b) (c) curves for 1c(50) under dry nitrogen atmosphere. 

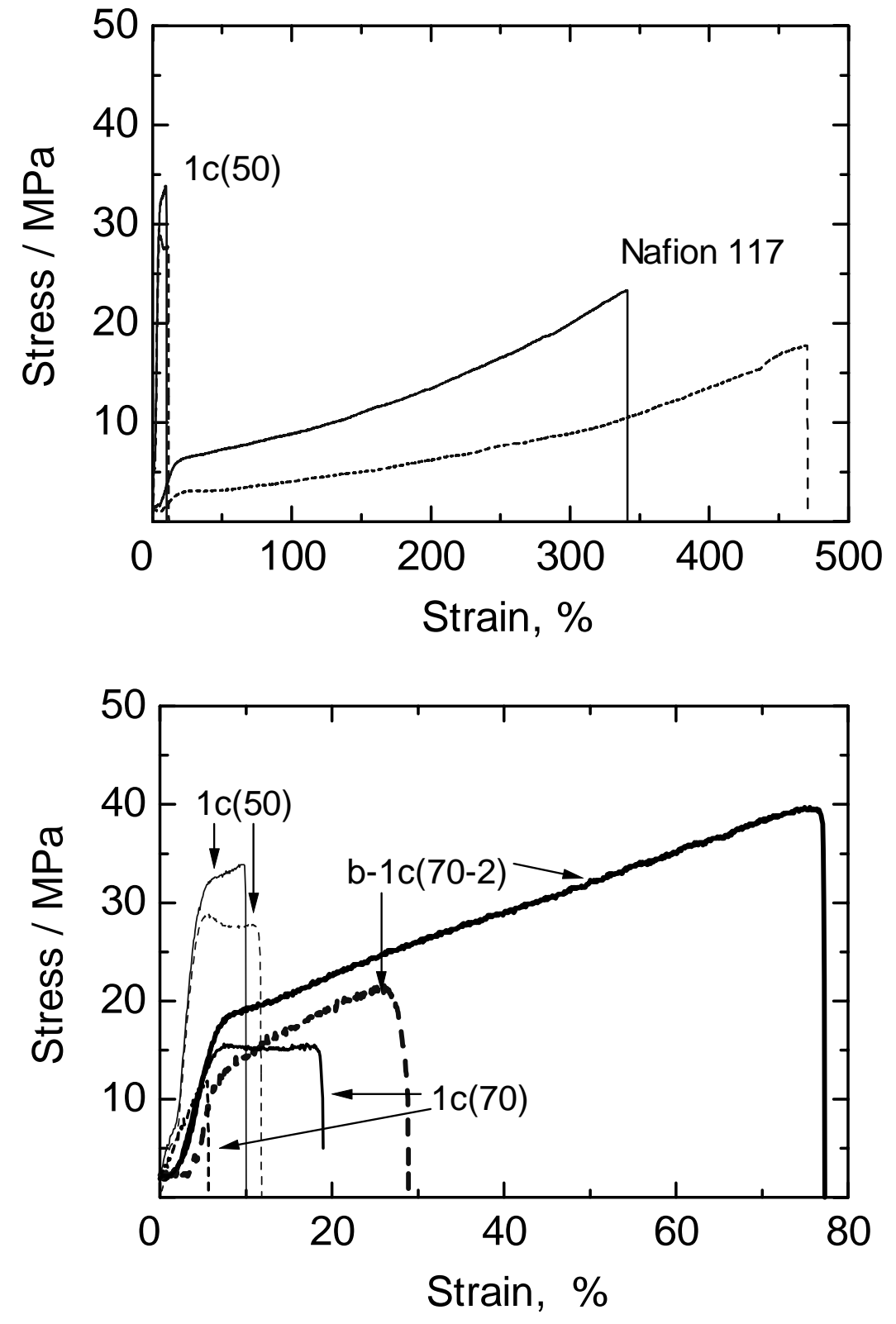

Figure S7. Stress versus strain curves of $1 \mathbf{c}(\mathbf{5 0}), \mathbf{1 c}(\mathbf{7 0}), \mathbf{b}-\mathbf{1 c}(\mathbf{7 0 - 2})$, and Nafion 117 at $85^{\circ} \mathrm{C}$ (solid) and $120^{\circ} \mathrm{C}$ (dotted), 93\% RH. 